Check for updates

Cite this: RSC Adv., 2017, 7, 42884

Received 23rd May 2017

Accepted 26th July 2017

DOI: $10.1039 / \mathrm{c} 7 \mathrm{ra05808j}$

rsc.li/rsc-advances

\title{
Fabrication of highly stable and sensitive electrochemical sensor from hemoglobin-Au nanocomposites and its analytical applications $\dagger$
}

\author{
Weiping Wu, \$ Yuting Fang, \$ Chenchen Zhu, Shiyu Chen, Ting Li, Lei Wu, Ning Bao, \\ Yang Liu (D) * and Haiying Gu (D) *
}

To improve electron transfer, a combination of electroactive hemoglobin $(\mathrm{Hb})$ and $\mathrm{Au}$ nanoparticles ( $\mathrm{Au}$ NPs) was designed to obtain nanocomposites (NCs). Cyclic voltammetry and redox probe characterization showed that $\mathrm{Hb}$-Au NCs incorporating the layer-by-layer technique to improve the ration of electroactive $\mathrm{Hb}$, showed a better conjugated structure, lower standard entropy, and faster electron transfer. Au entrapped in $\mathrm{Hb}$ on the glassy carbon electrode (GCE) also exhibited a wider linear range, and excellent reproducibility and recovery for analytical applications of hydrogen peroxide, oxygen, and trichloroacetic acid. Therefore, our research could potentially become a promising alternative by combining bioactive molecules with nanoparticles, and broaden the applications of mediator-free biosensors.

\section{Introduction}

Hemoglobin $(\mathrm{Hb})$ is a biomolecule with high, long-term stability. ${ }^{1,2}$ Fast electron transfer between $\mathrm{Hb}$ and electrode surfaces has been reported as not possible owing to deep embedding of the electroactive heme group. ${ }^{3,4}$ In recent decades, much effort has been made to increase electron transfer kinetics, with the most commonly used methods including specific surface modifications of electrodes with polymer films, ${ }^{5}$ surfactants, ${ }^{6-8}$ nanoparticles (NPs), ${ }^{9,10}$ and biomembranes..$^{11} \mathrm{Au}$ nanomaterials have excellent properties with respect to volume, surface, quantum size, macro quantum tunneling effect, and catalytic properties. ${ }^{12}$ Furthermore, Au NPs exhibit better catalytic activity toward hydrogen peroxide $\left(\mathrm{H}_{2} \mathrm{O}_{2}\right)$ than metallic gold due to their high surface-area-tovolume ratio and their interface-dominated properties. ${ }^{13}$ The immobilization of biomolecules, such as horseradish peroxidase, laccase, and cytochrome c, on Au NP surfaces to construct biosensors has been widely investigate. ${ }^{14-16}$ However, $\mathrm{Hb}$ and $\mathrm{Au}$ NP nanocomposites have rarely been reported.

Recently, the analysis of hydrogen peroxide $\left(\mathrm{H}_{2} \mathrm{O}_{2}\right)$, oxygen $\left(\mathrm{O}_{2}\right)$, and trichloroacetic acid (TCA) using various methods has attracted considerable attention. Traditional methods ${ }^{17-19}$ usually detect these species using expensive and sophisticated

Institute of Analytical Chemistry for Life Science, School of Public Health, Nantong University, Nantong 226019, China.E-mail: liuyang1982@ntu.edu.cn; hygu@ntu. edu.cn

† Electronic supplementary information (ESI) available. See DOI: 10.1039/c7ra05808j

\$ Both authors contributed equally. equipment, involving time-consuming and multistep procedures that have low sensitivity, poor reproducibility, and poor repeatability. Therefore, electrochemical biosensors are better choices for meeting these various demands. Furthermore, the application of Hb-loaded biosensors to electrochemical detection of multiple targets has seldom been reported.

Herein, we present a novel approach to constructing a biosensor for $\mathrm{H}_{2} \mathrm{O}_{2}, \mathrm{O}_{2}$, and TCA based on $\mathrm{Hb}$ electrochemistry. Au NPs and $\mathrm{Hb}-\mathrm{Au}$ NCs were alternately immobilized on a GCE using layer-by-layer technology. The resultant $\{\mathrm{Au} \mathrm{NP} /$ $\mathrm{Hb}-\mathrm{Au} \mathrm{NC}\}_{n}$ films showed direct and reversible electrochemistry of heme $\mathrm{Fe}(\mathrm{III}) / \mathrm{Fe}(\mathrm{II})$ redox couples. The $n$ (value of layer-bylayer) was optimized to 3 using a variety of electrochemical techniques. Owing to the outstanding bioelectrical catalytic abilities of the $\{\mathrm{Au} \mathrm{NPs} / \mathrm{Hb}-\mathrm{Au} \mathrm{NCs}\}_{3}$ films, the modified biosensor exhibited sensitive electrochemical responses to $\mathrm{H}_{2} \mathrm{O}_{2}, \mathrm{O}_{2}$, and TCA. This type of bionanocomposite maintains the natural biological activity of $\mathrm{Hb}$ and offers a more accurate and rapid alternative approach to electrochemical measurements for further research.

\section{Experimental}

\subsection{Materials and reagents}

$\mathrm{Hb}$ from bovine blood (lyophilized powder protein, $M_{\mathrm{w}} 64500$ ) was purchased from Sinopharm Chemical Reagent Co., Ltd (Shanghai, China). Potassium ferricyanide and $\mathrm{HAuCl}_{4} \cdot 4 \mathrm{H}_{2} \mathrm{O}$ (99.999\%; $\mathrm{Au} \%,>48 \%)$ were purchased from Sigma-Aldrich, USA. Sodium citrate $\left(\mathrm{Na}_{3} \mathrm{C}_{6} \mathrm{H}_{5} \mathrm{O}_{7}\right)$ was purchased from Shanghai No. 1 Reagent Factory. TCA $\left(\mathrm{C}_{2} \mathrm{HCl}_{3} \mathrm{O}_{2}\right)$ was purchased from Tokyo Chemistry Industry Corporation. Chitosan $(95 \%$ 
deacetylation, $M_{\mathrm{w}}$ 5.09105), $\mathrm{H}_{2} \mathrm{O}_{2}(30 \%)$ and other common chemicals were purchased from Aladdin Industrial Corporation. Other reagents were of analytical reagent grade. Phosphate buffers $(0.10 \mathrm{M})$ with different $\mathrm{pH}$ values were prepared by mixing standard solutions of $\mathrm{Na}_{2} \mathrm{HPO}_{4}$ and $\mathrm{NaH}_{2} \mathrm{PO}_{4}$, and adjusting the $\mathrm{pH}$ by adding $0.10 \mathrm{M} \mathrm{H}_{3} \mathrm{PO}_{4}$ or $0.10 \mathrm{M} \mathrm{NaOH}$ solutions. Double-distilled deionized (DI) water was used in all experiments. Deoxygenated water was obtained from DI water by bubbling through highly pure nitrogen for at least $30 \mathrm{~min}$.

\subsection{Apparatus}

Scanning electron microscopy (SEM) images were obtained with a JSM-6510 microscope (JEOL, Japan). Transmission electron microscopy (TEM) images were obtained with a JEM-2100 microscope (JEOL, Japan). Cyclic voltammetry (CV) and differential pulse voltammetry (DPV) were performed using a CHI660D electrochemical workstation (Shanghai Chenhua Instrument Company, China), and were operated in the electrochemical cell consisting of a modified GCE $(\Phi=3 \mathrm{~mm})$ as the working electrode, a platinum wire as the counter electrode, and a saturated calomel electrode (SCE) as the reference electrode. Phosphate buffer containing different concentrations of the detected materials was prepared by adding different amounts of the detected materials to deoxygenated phosphate buffer ( $8 \mathrm{~mL}, 0.1 \mathrm{M}, \mathrm{pH} 7.0$ ) using a microsyringe. CV signals were measured at room temperature (scan potential, -0.9 to $0.3 \mathrm{~V}$; scan rate, varied from 10 to $500 \mathrm{mV} \mathrm{s}^{-1}$; sensitivity (A/V), 1 $\times 10^{-6}$ ) for different electrochemical characterizations of GCE$\mathrm{CS}-\{\mathrm{Au} \mathrm{NPs} / \mathrm{Hb}-\mathrm{Au} \mathrm{NCs}\}_{3}$. DPV signals were measured at room temperature (scan potential, -0.9 to $0.3 \mathrm{~V}$; pulse amplitude, $0.05 \mathrm{~V}$; pulse width, $0.1 \mathrm{~s}$; sensitivity $\left.(\mathrm{A} / \mathrm{V}), 1 \times 10^{-6}\right)$ for quantitatively detection of the target analytes. Electrochemical impedance spectroscopy (EIS) was performed in $0.10 \mathrm{M} \mathrm{KCl}$ solution, containing $5 \mathrm{mM} \mathrm{Fe}(\mathrm{CN})_{6}{ }^{3-} / \mathrm{Fe}(\mathrm{CN})_{6}{ }^{4-}(1: 1)$ as a supporting electrolyte, at its open circuit potential using the
AUTOLAB PGSTAT 302N electrochemical working station (Metrohm Co. Ltd., Switzerland) (start frequency, $1.0 \times 10^{5} \mathrm{~Hz}$; end frequency, $5.0 \times 10^{-2} \mathrm{~Hz}$; frequency number, 60; amplitude of potential perturbation, $10 \mathrm{mV}$ ). A CHI 440B electrochemical analyzer (CHInstruments, Co., USA) was used to perform electrochemical quartz crystal microbalance (EQCM) measurements. Gold-coated quartz crystal resonator electrodes were soaked in freshly prepared "piranha" solution $\left(30 \% \mathrm{H}_{2} \mathrm{O}_{2}\right.$ and $98 \% \mathrm{H}_{2} \mathrm{SO}_{4}, 3: 7 \mathrm{v} / \mathrm{v}$ ) for $15 \mathrm{~min}$, and then washed with pure water. The zeta potential of the $\mathrm{Hb}-\mathrm{Au}$ NCs was measured using a Zetasizer Nano ZS-90 (Malvern, England). All measurements were performed at room temperature $\left(25 \pm 0.2^{\circ} \mathrm{C}\right)$ in a Faraday cage, unless otherwise specified. All solutions were deoxygenated by bubbling through highly pure nitrogen for at least 30 min under a nitrogen atmosphere, and were maintained throughout the measurement period.

\subsection{Synthesis of $\mathbf{H b}-\mathbf{A u} \mathbf{N C s}$ and biosensor construction}

$\mathrm{Au}$ NPs were prepared according to our previous work. ${ }^{20}$ The prepared Au NPs were stored in brown glass bottles at $4{ }^{\circ} \mathrm{C}$. $\mathrm{Hb}-$ $\mathrm{Au}$ NCs were synthesized from $\mathrm{Hb}$ solution $\left(3.0 \mathrm{mg} \mathrm{mL}^{-1}\right)$ and $\mathrm{Au}$ NPs $\left(0.1 \mathrm{mg} \mathrm{mL}{ }^{-1}\right)$ at the optimized volume ratio of $3: 1$, shown in Fig. S1. $\uparrow$ The mixed solution was sonicated for $30 \mathrm{~min}$, centrifuged at $5000 \mathrm{rpm}$ for $10 \mathrm{~min}$, and washed twice with DI water. Finally, the precipitates were dispersed in $\mathrm{pH} 7.0 \mathrm{PBS}$ to form $3.0 \mathrm{mg} \mathrm{mL}{ }^{-1}$ dispersions, which were stored in a refrigerator at $4{ }^{\circ} \mathrm{C}$. The zeta potential of the $\mathrm{Hb}-\mathrm{Au}$ NCs was $2.4 \pm$ $0.1 \mathrm{mV}$, as measured by a Zetasizer Nano ZS-90, which indicated that the $\mathrm{Hb}-\mathrm{Au}$ NCs were positively charged.

The bare GCE was polished with abrasive paper and alumina $(0.25$ and $0.05 \mu \mathrm{m})$ slurry on microcloth pads, ultrasonicated in DI water for $30 \mathrm{~s}$, and then dried under nitrogen. The detailed assembly process is illustrated in Scheme 1 . The chitosan (CS)modified glassy carbon electrode (GCE) was prepared according to our previous work. ${ }^{21}$ The CS modified glassy carbon electrode

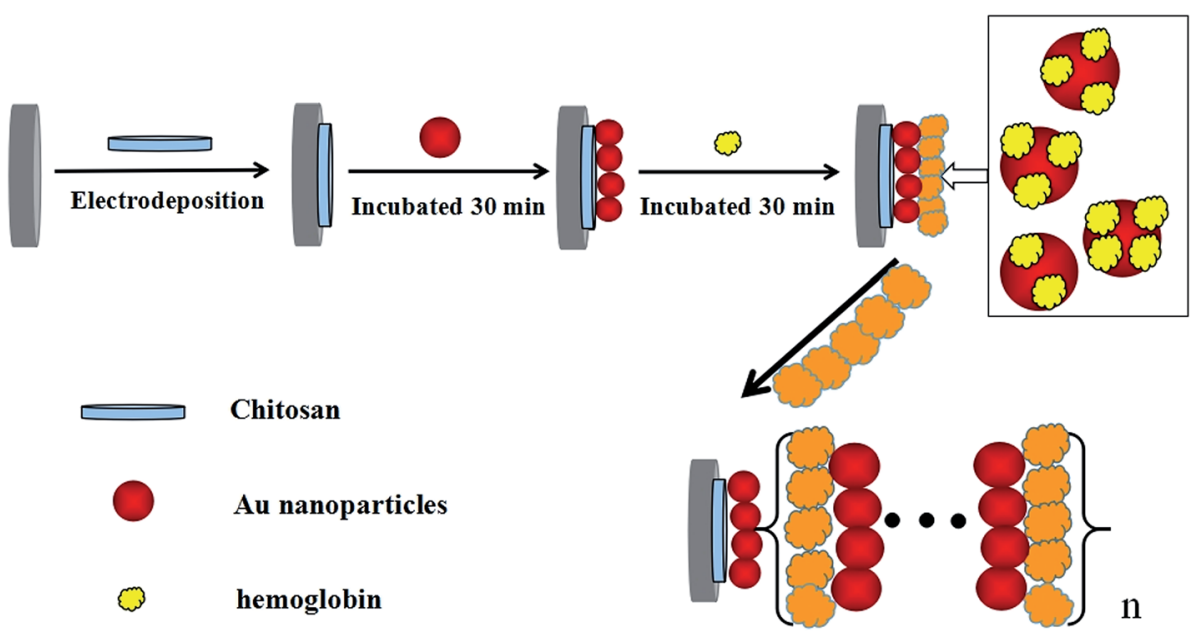

Au nanoparticles + hemoglobin (1:3)

Scheme 1 Assembly process of $\{\mathrm{Au} \mathrm{NPs} / \mathrm{Hb}-\mathrm{Au} \mathrm{NCs}\}_{n}$ immobilized on the GCEs. 
(CS-GCE) was then dipped into Au NPs at $4{ }^{\circ} \mathrm{C}$ for $30 \mathrm{~min}$, washed with DI water and dried at room temperature to form $\mathrm{Au}$ NP-CS modified GCE, denoted as Au-CS-GCE. Afterwards, the modified GCE was dropcast with $20 \mu \mathrm{L}$ of $3.0 \mathrm{mg} \mathrm{mL}{ }^{-1} \mathrm{Au}-\mathrm{Hb}$ NCs, dried at room temperature, and washed with DI water. The procedure was repeated for the optimal number of $\{\mathrm{Au} \mathrm{NPs} / \mathrm{Hb}-$ $\mathrm{Au} \mathrm{NCs}_{3}$ bilayers, using layer-by-layer technology to form GCECS- $\{\mathrm{Au} \mathrm{NPs} / \mathrm{Hb}-\mathrm{Au} \mathrm{NCs}\}_{3}$.

In the application of real samples, $0.1 \mathrm{M}$ zinc acetate and potassium ferrocyanide were added to a solution of milk powder (from a local market; $100 \mathrm{~mL}, 0.1 \mathrm{~g} \mathrm{~mL}^{-1}$ ) to remove proteins by centrifuging at $4000 \mathrm{rpm}$ for $5 \mathrm{~min}$. A $10 \mathrm{~mL}$ aliquot of the above supernatant was used for $\mathrm{H}_{2} \mathrm{O}_{2}$ recovery experiments. The tape was used for TCA and $\mathrm{O}_{2}$ recovery research without specific treatment. Recovery tests were carried out by adding different concentrations of standard $\mathrm{H}_{2} \mathrm{O}_{2}$, TCA, or $\mathrm{O}_{2}$ into the samples and comparing with the results of the national standard method. The standard methods for detecting $\mathrm{H}_{2} \mathrm{O}_{2}$, TCA, or $\mathrm{O}_{2}$ were iodine titrimetry, colorimetry, and gas chromatography, respectively.

\section{Results and discussion}

\subsection{Morphology of $\mathbf{H b}-\mathrm{Au}$ NCs}

TEM was used to determine the morphology and structure of the Au NPs and Hb-Au NCs. As shown in Fig. 1(A), the Au NPs had average diameters of about $25 \mathrm{~nm}$ and an almost uniform and clear surface. The morphology of the $\mathrm{Hb}-\mathrm{Au}$ NCs is shown in Fig. 1(B), in which an Au cluster was surrounded by polymer materials, and the surfaces of the $\mathrm{Au}$ NPs were hazy and aggregated, in contrast to the pure Au NPs. The Hb-Au NCs were also characterized by SEM. Hb-Au NCs were formed as a film on the electrode surface, into which the Au NPs were then enmeshed, as shown in Fig. 1(C). The porous structure of the $\mathrm{Hb}-\mathrm{Au}$ NCs might allow the small ions in the buffers to pass through the films easily, which would be beneficial to $\mathrm{Hb}$ electron transfer in the films with underlying electrodes.

\subsection{Electrochemical characterization of $\mathrm{Hb}-\mathrm{Au}$ NCs}

No cyclic voltammetry (CV) peaks were observed for the bare GCE (curve a), CS-GCE (curve b), and Au-CS-GCE (curve c) in the selected potential range, as shown in Fig. S2. $\dagger$ A pair of welldefined, nearly reversible redox peaks at $-0.312 \mathrm{~V}$ and $-0.376 \mathrm{~V}$ were observed when $\mathrm{Hb}$-Au NCs were modified on the $\mathrm{Au}-\mathrm{CS}-\mathrm{GCE}$ (curve d), indicating the successful assembly of $\mathrm{Hb}-$ $\mathrm{Au}$ NCs. According to the results of EIS in Fig. S3, $\uparrow$ with the assembly of $\{\mathrm{Au} \mathrm{NPs} / \mathrm{Hb}-\mathrm{Au} \mathrm{NCs}\}_{n}$, the diameter of impedance increased with the layer number (curve e-h), indicating successful assembly of the $\mathrm{Hb}-\mathrm{Au}$ NPs. ${ }^{22,23}$

The value of the redox current of $\{\mathrm{Au} \mathrm{NPs} / \mathrm{Hb}-\mathrm{Au} \mathrm{NCs}\}_{n}$ reached a clear maximum at $n=3$ (Fig. 2). The assembly process was mainly based on electrostatic interactions and the "A-N" chemical bond between the Hb-Au NCs and Au NPs. ${ }^{24,25} \mathrm{Hb}$ is positively charged in $\mathrm{pH}$ 6.0 PBS due to its isoelectric point (pI) of 7.4, and can be adsorbed on oppositely-charged Au NPs by electrostatic attraction to form $\mathrm{Hb}-\mathrm{Au}$ NCs. The zeta potential of the $\mathrm{Hb}-\mathrm{Au} \mathrm{NCs}$ was measured as $2.4 \pm 0.1 \mathrm{mV}$, indicating that the $\mathrm{Hb}-\mathrm{Au}$ NCs held positive charges. Therefore, we used negatively charged Au NPs to realize layer-by-layer $\mathrm{Hb}-\mathrm{Au}$ NCs on the GCE surface. The EQCM technique has also been shown to be valuable for studying surface-related processes in liquids, including protein adsorption, ${ }^{22,23}$ using the Sauerbrey equation, ${ }^{24}$

$$
\Delta f=\frac{-1.45 \times 10^{8} \Delta m}{A}
$$

where $A$ is the geometric area of the QCM electrode $\left(0.196 \mathrm{~cm}^{2}\right)$. According to the EQCM results (Table S1 $\dagger$ ), the $\Delta f$ values of the $\{\mathrm{Au} \mathrm{NPs} / \mathrm{Hb}-\mathrm{Au} \mathrm{NCs}\}_{n}$ films absorption steps $(n=8)$ were $44.1 \pm 3.2\left(\{\mathrm{Au} \mathrm{NPs} / \mathrm{Hb}-\mathrm{Au} \mathrm{NCs}\}_{1}\right), 89.1 \pm 5.2(\{\mathrm{Au}$ $\left.\mathrm{NPs} / \mathrm{Hb}-\mathrm{Au} \mathrm{NCs}\}_{2}\right), 135.1 \pm 6.9\left(\{\mathrm{Au} \mathrm{NPs} / \mathrm{Hb}-\mathrm{Au} \mathrm{NCs}\}_{3}\right)$, and $180.1 \pm 4.0 \mathrm{~Hz}\left(\{\mathrm{Au} \mathrm{NPs} / \mathrm{Hb}-\mathrm{Au} \mathrm{NCs}\}_{4}\right)$. The corresponding total film masses were 59.13, 119.88, 181.98, and $244.08 \mu \mathrm{g}$, respectively. As the geometric area of the EQCM electrode was $0.196 \mathrm{~cm}^{2}$ and the molecular mass of $\mathrm{Hb}$ was 64500 , the surface concentrations of total $\mathrm{Hb}$ in each film were $4.67 \times$ $10^{-9}, 9.48 \times 10^{-9}, 14.3 \times 10^{-9}$, and $17.73 \times 10^{-9} \mathrm{~mol} \mathrm{~cm}^{-2}$,
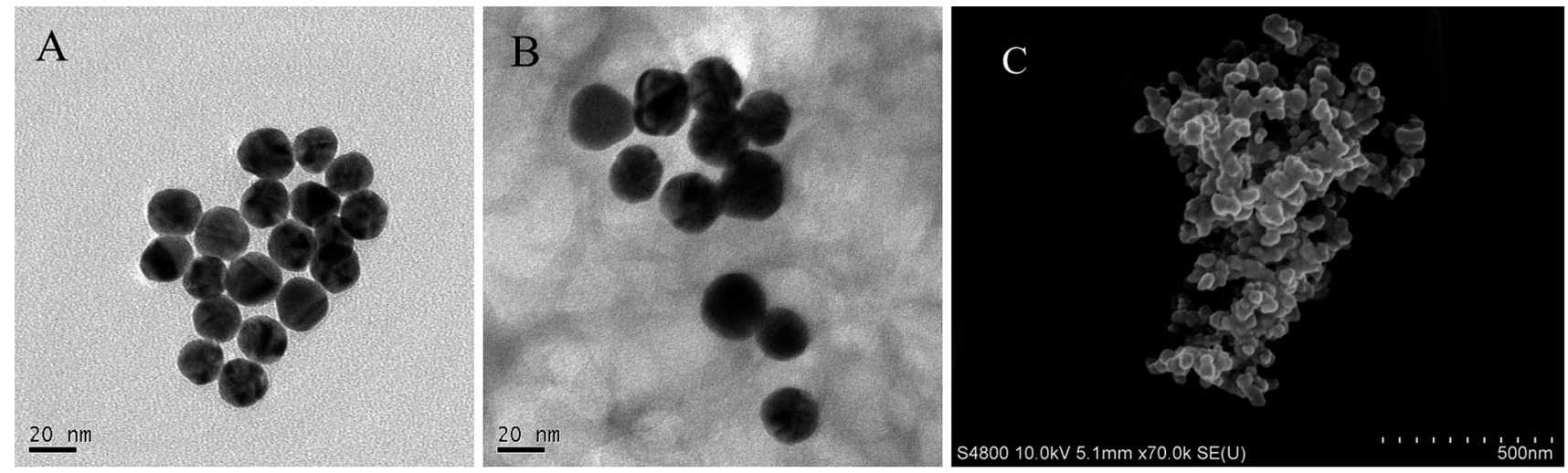

Fig. 1 TEM images of (A) Au NPs and (B) Hb-Au NCs at $100000 \times$ magnification. SEM images of (C) Hb-Au NCs at $70000 \times$ magnification on a GCE. 

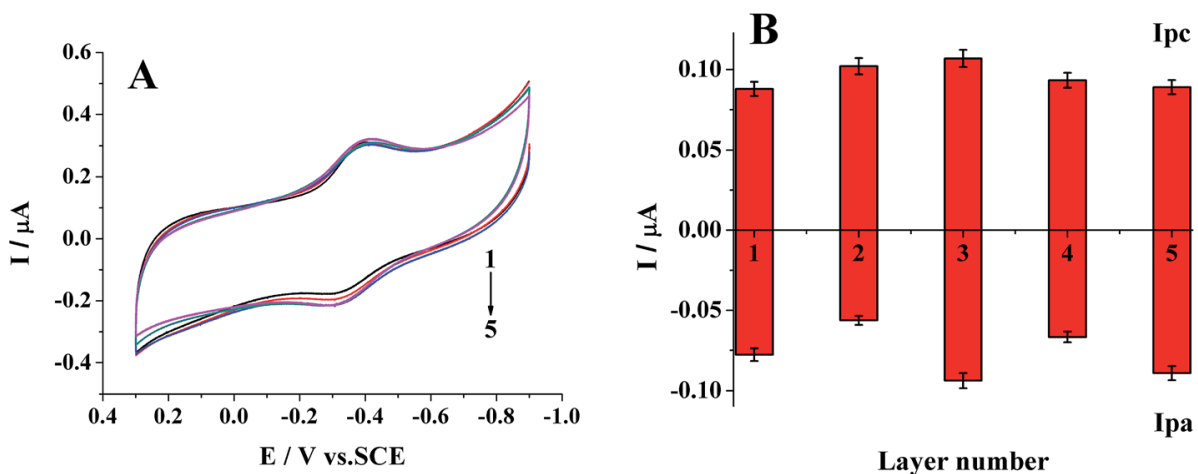

Layer number

Fig. 2 (A) Cyclic voltammograms of $\{\mathrm{Au} \mathrm{NPs} / \mathrm{Hb}-\mathrm{Au} \mathrm{NCs}\}_{n}$ films immobilized on CS-modified GCEs at $100 \mathrm{mV} \mathrm{s}{ }^{-1}$ in $\mathrm{pH} 7.0 \mathrm{PBS}(n=1-5$; scan potential from -0.9 to $0.3 \mathrm{~V}$ ). (B) Redox peak currents varied with number of layers (from 1 to 5 ).

respectively. The surface concentration of electroactive $\mathrm{Hb}$ in the films could be calculated according to the equation $\Gamma=$ $Q /(n F A)$, where $Q$ is the charge involved in the reaction, $n$ is the electron transfer number, $F$ is the Faraday constant, and $A$ is the geometric area of the GCE. The amounts of electroactive $\mathrm{Hb}$ molecules were estimated to be $6.543 \times 10^{-10}, 7.499 \times$ $10^{-10}, 9.338 \times 10^{-10}$, and $9.350 \times 10^{-10} \mathrm{~mol} \mathrm{~cm}^{-2}$ in each film, respectively. The ration of electroactive $\mathrm{Hb}$ to total $\mathrm{Hb}$ on the electrode was $13.8,7.91,6.53$, and $5.27 \%$. The ration of electroactive $\mathrm{Hb}$ increased with increasing $n$, from 1 to 3 , and tended to level off when $n$ was more than 3 . This may be due to the fourth layer being too far away from the Au electrode to perform direct electrochemistry. Consequently, the concentration of electroactive $\mathrm{Hb}$ in the third and fourth films was almost equal. Therefore, $\{\mathrm{Au} \mathrm{NPs} / \mathrm{Hb}-\mathrm{Au} \mathrm{NCs}\}_{3}$ were chosen as the optimal layer-by-layer experimental conditions for further investigation.

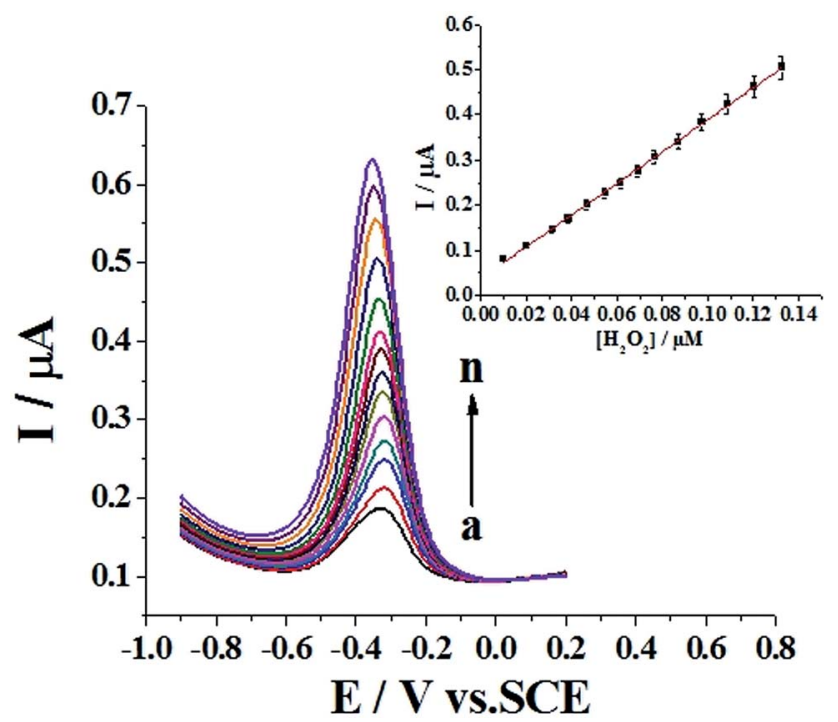

Fig. 3 Differential pulse voltammetry (DPV) signals measured at room temperature (scan potential, -0.9 to $0.3 \mathrm{~V}$; pulse amplitude, $0.05 \mathrm{~V}$; pulse width, $0.1 \mathrm{~s}$, sensitivity (A/V), $1 \times 10^{-6}$ ) for GCE-CS-\{Au NPs/Hb$\mathrm{Au} \mathrm{NCs}\}_{3}$ in PBS $(0.10 \mathrm{M}, \mathrm{pH} 7.0)$ within the $\mathrm{H}_{2} \mathrm{O}_{2}$ concentration range $1.00 \times 10^{-8}$ (curve a) to $1.76 \times 10^{-7} \mathrm{M}$ (curve $\mathrm{n}$ ) at a scan rate of $100 \mathrm{mV} \mathrm{s}^{-1}$. Inset: plot of current vs. $\mathrm{H}_{2} \mathrm{O}_{2}$ concentration.
As depicted in Fig. S4, $\uparrow$ the electron transfer number $(n)$ of $\left\{\mathrm{Au} \mathrm{NPs} / \mathrm{Hb}-\mathrm{Au} \mathrm{NCS}_{3}\right.$ on the electrode was found to be 1 , implying a single electron transfer reaction. These results demonstrated that $\mathrm{Hb}$ realized direct electron transfer, indicating mutual transmission between ferrous iron and ferric iron. The proportion of protons/electrons involved was estimated to be 1, as shown in Fig. S5. $\dagger$ Therefore, the electrontransfer reaction can be presented as: ${ }^{25}$

$$
\mathrm{HbhemeFe}^{3+}+\mathrm{H}^{+}+\mathrm{e} \rightleftharpoons \mathrm{HbhemeFe}^{2+}
$$

When $n \Delta E_{\mathrm{p}}<200 \mathrm{mV}$, the electron transfer rate constant $\left(k_{\mathrm{s}}\right)$ was estimated using Laviron's equation: ${ }^{26}$

$$
\begin{aligned}
\log k_{\mathrm{s}}= & \alpha \log (1-\alpha)+(1-\alpha) \log \alpha-\log \frac{R T}{n F \nu} \\
& -\frac{\alpha(1-\alpha) n F \Delta E_{\mathrm{p}}}{2.3 R T}
\end{aligned}
$$

where $\alpha$ is the charge transfer coefficient. ${ }^{10}$ When the scan rate was $100 \mathrm{mV} \mathrm{s}^{-1}$ and $\Delta E_{\mathrm{p}}=80 \mathrm{mV}, k_{\mathrm{s}}$ was calculated to be

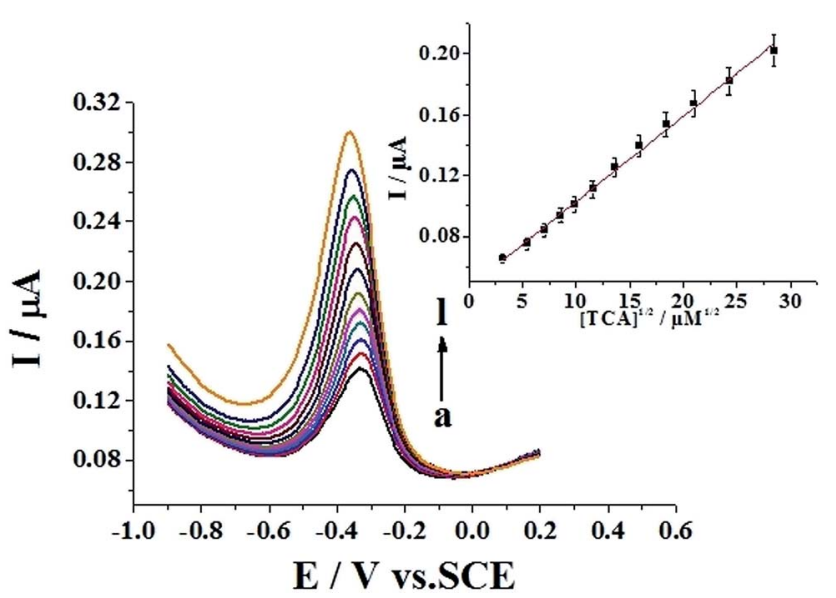

Fig. 4 DPV signals measured at room temperature (scan potential, -0.9 to $0.3 \mathrm{~V}$; pulse amplitude, $0.05 \mathrm{~V}$; pulse width, $0.1 \mathrm{~s}$, sensitivity (A/ V), $1 \times 10^{-6}$ ) for GCE-CS-\{Au NPs/Hb-Au NCs $\}_{3}$ in PBS $(0.10 \mathrm{M}, \mathrm{pH}$ 7.0) within the TCA concentration range $1.00 \times 10^{-11}$ (curve a) to 8.10 $\times 10^{-10} \mathrm{M}$ (curve l) at a scan rate of $100 \mathrm{mV} \mathrm{s}^{-1}$. Inset: plot of current vs. square root of TCA concentration. 
$0.95 \mathrm{~s}^{-1}$, which was larger than the value of $0.49 \mathrm{~s}^{-1}$ reported for an $\mathrm{Au}$ colloid-cysteamine-modified gold electrode. ${ }^{4}$

\subsection{Biosensors based on electrocatalysis of GCE-CS- $-\mathrm{Au}$ NPs/Hb-Au NCs $\}_{3}$}

DPV is a measurement method that imposes a range of pulsed voltages (10-100 $\mathrm{mV}$ ) on a direct current voltage, which can improve sensitivity. ${ }^{27,28}$ Therefore, we selected DPV for analyte determination instead of CV. The electrocatalysis of $\mathrm{H}_{2} \mathrm{O}_{2}$ using GCE-CS- $\left\{\mathrm{Au} \mathrm{NPs} / \mathrm{Hb}-\mathrm{Au} \mathrm{NCs}_{3}\right.$ was investigated with the successive addition of $\mathrm{H}_{2} \mathrm{O}_{2}$ to $\mathrm{pH}$ 7.0 PBS under a nitrogen atmosphere, and an obvious increase in the cathodic peak current at approximately $-0.328 \mathrm{~V}$ was observed (Fig. 3). The more $\mathrm{H}_{2} \mathrm{O}_{2}$ added to the continuously stirred deoxygenated buffer solution, the larger the cathodic peak current became, indicating that $\mathrm{Hb}$ incorporated in the composite film acted as an effective catalyst for $\mathrm{H}_{2} \mathrm{O}_{2}$ reduction. The inset shows the calibration curve of the amperometric current and $\mathrm{H}_{2} \mathrm{O}_{2}$

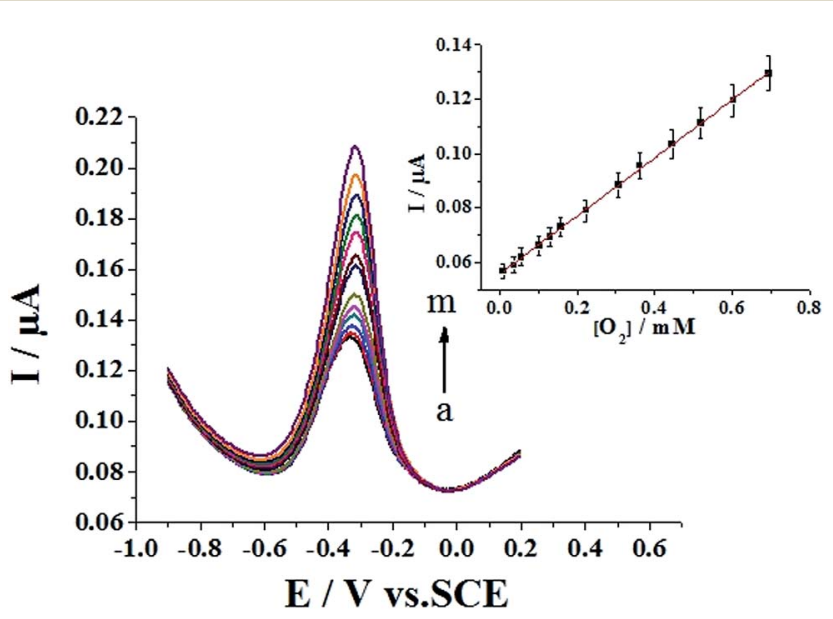

Fig. 5 DPV signals measured at room temperature (scan potential, -0.9 to $0.3 \mathrm{~V}$; pulse amplitude, $0.05 \mathrm{~V}$; pulse width, $0.1 \mathrm{~s}$, sensitivity (A/ V), $1 \times 10^{-6}$ ) for GCE-CS-\{Au NPs/Hb-Au NCs $\}_{3}$ in PBS $(0.10 \mathrm{M}, \mathrm{pH}$ 7.0) within $\mathrm{O}_{2}$ concentration range $9.28 \times 10^{-6}$ (curve a) to $6.96 \times$ $10^{-4} \mathrm{M}$ (curve $\mathrm{m}$ ) at a scan rate of $100 \mathrm{mV} \mathrm{s}^{-1}$. Inset: plot of current vs. $\mathrm{O}_{2}$ concentration. concentration. Excellent linear relationships were obtained in the concentration range $9.70 \times 10^{-9}$ to $2.14 \times 10^{-5} \mathrm{M}(\mathrm{a}-\mathrm{n})$ $\left(R^{2}=0.9990, n=8\right)$. This relationship can be described as $I_{\mathrm{A}}=$ $3.68 \times 10^{-7}+3.52 C_{\mathrm{H}_{2} \mathrm{O}_{2}}$, M. The limit of detection (LOD) of this biosensor for $\mathrm{H}_{2} \mathrm{O}_{2}$ was estimated as $3.55 \times 10^{-9} \mathrm{M}$ at a signalto-noise ratio of $3(\mathrm{~S} / \mathrm{N}=3)$. The mechanism can be expressed using the following equation: ${ }^{29}$

$$
\text { HbhemeFe }{ }^{2+}+\mathrm{H}_{2} \mathrm{O}_{2}+\mathrm{e} \rightarrow \mathrm{HbhemeFe}^{3+}+\mathrm{H}_{2} \mathrm{O}
$$

TCA is an important chemical intermediate in the synthesis of organic compounds and a by-product in drinking water disinfected with chlorine. ${ }^{30}$ The electrocatalytic reduction of TCA by GCE-CS- $\{\mathrm{Au} \text { NPs/Hb-Au NCs }\}_{3}$ is shown in Fig. 4.

When different concentrations of TCA were added to $\mathrm{pH} 7.0$ PBS under a nitrogen atmosphere, an obvious reduction peak at $-0.340 \mathrm{~V}$ was observed. The catalytic reduction peak current increased linearly with the square root of TCA concentration in the solution. The linear regression equation was $I_{\mathrm{A}}=2.7279 \times$ $10^{-8}+1.32843 \times 10^{-4} C_{\mathrm{TCA}^{1 / 2}}, \mathrm{M}\left(R^{2}=0.9993, n=8\right)$. The linear relationship was obtained in the concentration range $5.00 \times$ $10^{-11}$ to $8.10 \times 10^{-6} \mathrm{M}$ with an LOD of $3.07 \times 10^{-11} \mathrm{M}$. The bioelectrocatalytic reduction mechanism of TCA by the sensor can be expressed as: ${ }^{31}$

$$
\begin{aligned}
2 \mathrm{HbhemeFe}^{2+}+\mathrm{CCl}_{3} \mathrm{COOH}+\mathrm{H}^{+}+\mathrm{e} \rightarrow \\
2 \mathrm{HbhemeFe}^{3+}+\mathrm{Cl}_{2} \mathrm{HCCOOH}+\mathrm{Cl}^{-}
\end{aligned}
$$

GCE-CS- $\{\mathrm{Au} \text { NPs/Hb-Au NCs }\}_{3}$ was then studied as a biosensor for $\mathrm{O}_{2}$. By continuously injecting an amount of pure $\mathrm{O}_{2}$ into thoroughly-deoxygenated PBS $(5.0 \mathrm{~mL}, \mathrm{pH} 7.0)$ under a nitrogen atmosphere, the electrocatalytic current at about $-0.332 \mathrm{~V}$ increased with increasing $\mathrm{O}_{2}$ concentration, indicating that $\mathrm{O}_{2}$ was reduced by GCE-CS $-\{\mathrm{Au} \mathrm{NPs} / \mathrm{Hb}-\mathrm{Au} \mathrm{NCs}\}_{3}$. The peak current increased linearly with increasing oxygen concentration, as shown in Fig. 5. The biosensor exhibited an excellent oxygen sensing ability within the range $9.28 \times 10^{-6}$ to $6.96 \times 10^{-4} \mathrm{M}(\mathrm{a}-\mathrm{m})$. The linear equation was $I_{\mathrm{A}}=5.57711 \times$

\begin{tabular}{|c|c|c|c|c|}
\hline \multirow[t]{3}{*}{$\mathrm{O}_{2}$} & Red blood cell on $\mathrm{Au}-\mathrm{NP} / \mathrm{GCE}$ & $2.0 \times 10^{-3}$ to $8.0 \times 10^{-3} \mathrm{M}$ & $2.0 \times 10^{-3} \mathrm{M}$ & 32 \\
\hline & $\mathrm{TiO}_{2}$ and Nafion film modified GCE & $0.3-10 \mathrm{mg} \mathrm{L}^{-1}$ & $0.12 \mathrm{mg} \mathrm{L}^{-1}$ & 33 \\
\hline & GCE-CS- $\{\mathrm{Au} \text { NPs/Hb-Au NCs }\}_{3}$ & $9.28 \times 10^{-6}$ to $6.96 \times 10^{-4} \mathrm{M}$ & $3.1 \times 10^{-6} \mathrm{M}$ & This work \\
\hline \multirow[t]{2}{*}{$\mathrm{H}_{2} \mathrm{O}_{2}$} & $\mathrm{Hb}$ on $\mathrm{Au}$ NPs & $3.6 \times 10^{-7}$ to $8.6 \times 10^{-3} \mathrm{M}$ & $1.2 \times 10^{-7} \mathrm{M}$ & 4 \\
\hline & $\mathrm{Hb}$ on $\mathrm{Fe}_{3} \mathrm{O}_{4} @ P t$ NPs & $2.8 \times 10^{-6}$ to $1.4 \times 10^{-3} \mathrm{M}$ & $4.8 \times 10^{-8} \mathrm{M}$ & 34 \\
\hline \multirow[t]{4}{*}{ TCA } & $\begin{array}{l}\text { Horseradish peroxidase on gemini surfactant-polyvinyl } \\
\text { alcohol composite film }\end{array}$ & $2.0 \times 10^{-5}$ to $1.0 \times 10^{-2} \mathrm{M}$ & $5.7 \times 10^{-3} \mathrm{M}$ & 36 \\
\hline & $\mathrm{Fe}_{3} \mathrm{O}_{4} @ \mathrm{Au}-\mathrm{CS}$ modified GCE & $1.60 \times 10^{-6}$ to $4.80 \times 10^{-3} \mathrm{M}$ & $1.0 \times 10^{-6} \mathrm{M}$ & 25 \\
\hline & $\mathrm{Hb}$ on multi-walled carbon nanotubes & $5.0 \times 10^{-4}$ to $1.2 \times 10^{-2} \mathrm{M}$ & $1.0 \times 10^{-4} \mathrm{M}$ & 37 \\
\hline & GCE-CS- $\{\mathrm{Au} \text { NPs/Hb-Au NCs }\}_{3}$ & $5.0 \times 10^{-11}$ to $8.1 \times 10^{-6} \mathrm{M}$ & $3.07 \times 10^{-11} \mathrm{M}$ & This work \\
\hline
\end{tabular}
$10^{-8}+1.06592 \times 10^{-4} C_{\mathrm{O}_{2}}, \mathrm{M}\left(R^{2}=0.9995, n=8\right)$, and the LOD

Table 1 Comparison of detection and quantification limits obtained in this work with those reported in the literature 
Table 2 Analytical application of GCE-CS- $\{\mathrm{Au} \mathrm{NPs} / \mathrm{Hb}-\mathrm{Au} \mathrm{NCs}\}_{3}$ to real samples

\begin{tabular}{|c|c|c|c|c|c|c|}
\hline & \multicolumn{4}{|c|}{$\underline{\mathrm{DPV}}$ at the GCE-CS- $\{\mathrm{Au} \mathrm{NPs} / \mathrm{Hb}-\mathrm{Au} \mathrm{NCs}\}_{3}$} & \multicolumn{2}{|c|}{ Standard method } \\
\hline & Amount added & Amount found & Average recovery (\%) & $\operatorname{RSD} \%(n=3)$ & Averaged value & $\mathrm{RSD} \%(n=3)$ \\
\hline \multirow[t]{3}{*}{ TCA } & $8.6 \times 10^{-11}$ & $8.28 \times 10^{-11}$ & 96.29 & 6.22 & $8.70 \times 10^{-11 a}$ & 3.28 \\
\hline & $1.86 \times 10^{-10}$ & $1.95 \times 10^{-10}$ & 104.97 & 4.34 & $1.79 \times 10^{-10 a}$ & 4.22 \\
\hline & $5.9 \times 10^{-9}$ & $5.71 \times 10^{-9}$ & 96.84 & 4.56 & $6.00 \times 10^{-10 a}$ & 4.55 \\
\hline \multirow[t]{3}{*}{$\mathrm{O}_{2}$} & 0 & $9.74 \times 10^{-5}$ & $\mathrm{~N}$ & 5.77 & $9.23 \times 10^{-5 b}$ & 2.55 \\
\hline & $3.62 \times 10^{-4}$ & $3.74 \times 10^{-4}$ & 103.24 & 6.23 & $3.61 \times 10^{-4 b}$ & 2.10 \\
\hline & $6.03 \times 10^{-4}$ & $5.99 \times 10^{-4}$ & 99.27 & 4.35 & $6.01 \times 10^{-4 b}$ & 1.99 \\
\hline \multirow[t]{3}{*}{$\mathrm{H}_{2} \mathrm{O}_{2}$} & $8 \times 10^{-10}$ & $7.76 \times 10^{-10}$ & 97.01 & 3.36 & $7.99 \times 10^{-10 c}$ & 5.87 \\
\hline & $3.4 \times 10^{-9}$ & $3.28 \times 10^{-9}$ & 96.36 & 4.12 & $3.23 \times 10^{-9 c}$ & 6.10 \\
\hline & $1.31 \times 10^{-8}$ & $1.33 \times 10^{-8}$ & 101.45 & 4.23 & $1.33 \times 10^{-8 c}$ & 5.91 \\
\hline
\end{tabular}

was calculated as $3.10 \times 10^{-6} \mathrm{M}(\mathrm{S} / \mathrm{N}=3)$. The bioelectrocatalytic reduction mechanism of $\mathrm{O}_{2}$ by the modified biosensor can be expressed by the following equation: $:^{25}$

$$
2 \mathrm{HbhemeFe}^{2+}+4 \mathrm{H}^{+}+\mathrm{O}_{2}+2 \mathrm{e} \rightarrow 2 \mathrm{HbhemeFe}^{3+}+2 \mathrm{H}_{2} \mathrm{O}
$$

Table 1 shows the determination of $\mathrm{H}_{2} \mathrm{O}_{2}$, TCA, and $\mathrm{O}_{2}$ by different sensors. The results show that the linear range and detection limits achieved in this work were better than those in some previous reports.

\subsection{Application of GCE-CS- $\{\mathrm{Au} \mathrm{NPs} / \mathrm{Hb}-\mathrm{Au} \mathrm{NCs}\}_{3}$ to real sample analysis}

$\mathrm{H}_{2} \mathrm{O}_{2}$, applied in food anticorrosion, and is widely used in food production, processing, and packaging materials to kill harmful microbes and improve the storage period. $\mathrm{H}_{2} \mathrm{O}_{2}$ reportedly accelerates the aging and cancer by damaging cells. Some foods contain illegally added $\mathrm{H}_{2} \mathrm{O}_{2} \cdot{ }^{38}$ The results of detecting $\mathrm{H}_{2} \mathrm{O}_{2}$ in milk powder are listed in Table 2, which clearly showed that the consequences of the proposed biosensor and the Chinese national standard were similar, indicating the excellent reliability of the biosensor. The recovery experiment concentration of TCA and $\mathrm{O}_{2}$ was carried out in tap water as a real sample. The recoveries of the biosensor for TCA and $\mathrm{O}_{2}$ were calculated to be $96.29-104.97 \%$ and $99.27-103.24 \%$, respectively. The results showed that the detection method for $\mathrm{H}_{2} \mathrm{O}_{2}, \mathrm{O}_{2}$, and TCA presented in this work can be valid for analysis of real samples.

\section{Conclusions}

We have successfully constructed a biosensor based on $\mathrm{Hb}-\mathrm{Au}$ NCs using a layer-by-layer technique. Immobilized $\mathrm{Hb}$ on the electrode showed well-maintained bioactivity and enhanced electron transfer kinetics. The prepared biosensor achieved rapid and sensitive electrochemical responses to $\mathrm{H}_{2} \mathrm{O}_{2}$, TCA, and $\mathrm{O}_{2}$ without the addition of electron mediators. This strategy could potentially become a general and promising alternative to other bioactive molecules in various biosensor designs.

\section{Conflicts of interest}

There are no conflicts to declare.

\section{Acknowledgements}

This work was financially supported by the National Natural Science Foundation of China (Grant numbers: 21475070; 21175075; 21375066 and 81202249), the Natural Science Foundation of Jiangsu Province (Grant number: BK2011047, BK20151267), a Project Funded by "Six Kinds of Talents" in Jiangsu Province (2015-YY-008), a project funded by "College Students' Innovative Training Program" in Jiangsu Province (201610304035Z), and a project funded by China Environmental Protection Foundation.

\section{Notes and references}

1 K. Charradi, C. Gondran, A. B. H. Amara, V. Prevot and C. Mousty, Electrochim. Acta, 2009, 54, 4237-4244.

2 N. Q. Jia, Q. Lian, Z. Y. Wang and H. B. Shen, Sens. Actuators, $B, 2009,137,230-234$.

3 Y. Liu, Q. Y. Jiang, S. Y. Lu, Y. Zhang and H. Y. Gu, Appl. Biochem. Biotechnol., 2009, 152, 418-427.

4 H. Y. Gu, A. M. Yu and H. Y. Chen, J. Electroanal. Chem., 2001, 516, 119-126.

5 S. M. Chen and C. C. Tseng, Electrochim. Acta, 2004, 49, 19031914.

6 Y. S. Wang, R. Guo and J. Q. Xi, J. Colloid Interface Sci., 2009, 331, 470-475.

7 O. Y. Nadzhafova, V. N. Zaitsev, M. V. Drozdova, A. Vaze and J. F. Rusling, Electrochem. Commun., 2004, 6, 205-209.

8 J. M. Xu, W. Li, Q. F. Yin, H. Zhong, Y. L. Zhu and L. T. Jin, J. Colloid Interface Sci., 2007, 315, 170-176.

9 C. L. Xiang, Y. J. Zou, L. X. Sun and F. Xu, Sens. Actuators, B, 2009, 136, 158-162.

10 J. M. Gong and X. G. Lin, Microchem. J., 2003, 75, 51-57. 
11 Y. Hu, H. Sun and N. F. Hu, J. Colloid Interface Sci., 2007, 314, 131-140.

12 I. Taurino, G. Sanzò, R. Antiochia, C. Tortolini, F. Mazzei, G. Favero, G. D. Micheli and S. Carrara, Anal. Chem., 2016, 79, 151-159.

13 A. K. M. Kafi, A. Ahmadalinezhad, J. P. Wang, D. F. Thomas and A. C. Chen, Biosens. Bioelectron., 2010, 25, 2458-2463.

14 Y. Wang, X. L. Ma, Y. Wen, G. P. Duan, W. Ren, Z. R. Zhang and H. F. Yang, Microchim. Acta, 2009, 166, 283-288.

15 M. A. Rahman, H. B. Noh and Y. B. Shim, Anal. Chem., 2008, 80, 8020-8027.

16 Y. Li, J. Li, X. H. Xia and S. Q. Liu, Talanta, 2010, 82, 11641169.

17 M. C. Prieto-Blanco, M. F. Alpendurada, P. López-Mahía, S. Muniategui-Lorenzo, D. Prada-Rodríguez, S. Machado and C. Gonçalves, Talanta, 2012, 94, 90-98.

18 M. J. Cardador and M. Gallego, J. Chromatogr. B: Anal. Technol. Biomed. Life Sci., 2010, 878, 1824-1830.

19 P. S. Simone Jr, P. L. Ranaivo, G. Geme, M. A. Brown and G. L. Emmert, Anal. Chim. Acta, 2009, 654, 133-140.

20 C. M. Yu, L. Wang, W. B. Li, C. Zhu, N. Bao and H. Y. Gu, Sens. Actuators, B, 2015, 211, 17-24.

21 Z. Q. Pan, C. G. Shi, H. Fan, N. Bao, C. M. Yu, Y. Liu, R. Lu, Q. H. Zhang and H. Y. Gu, Sens. Actuators, B, 2012, 174, 421426.

22 M. J. Song, S. W. Hwang and D. Whang, Talanta, 2010, 80, 1648-1652.

23 L. G. Yu, G. M. Zhang, Y. Wu, X. Bai and D. Z. Guo, J. Cryst. Growth, 2008, 310, 3125-3130.
24 A. J. Bard and L. R. Faulkner, Electrochemical Methods, Chichester Brisbane Toronto, New York, 1980, ch. 9.

25 Y. Liu, T. Han, C. Chen, N. Bao, C. M. Yu and H. Y. Gu, Electrochim. Acta, 2011, 56, 3238-3247.

26 E. Laviron, J. Electroanal. Chem., 1979, 101, 19-28.

27 W. Lu, J. Ge, L. Tao, X. Cao, J. Dong and W. Qian, Electrochim. Acta, 2014, 130, 335-343.

28 M. K. Bojdi, M. H. Mashhadizadeh, M. Behbahani, A. Farahani, S. S. H. Davarani and A. Bagheri, Electrochim. Acta, 2014, 136, 59-65.

29 A. E. F. Nassar, Z. Zhang, V. Chynwat, H. A. Frank and J. F. Rusling, J. Phys. Chem., 1995, 99, 11013-11017.

30 J. Dojlido, E. Zbieć and R. Ŝwietlik, Water Res., 1999, 33, 3111-3118.

31 J. W. Shie, U. Yogeswaran and S. M. Chen, Talanta, 2009, 78, 896-902.

32 X. D. Wang and O. S. Wolfbeis, Chem. Soc. Rev., 2014, 43, 3666-3761.

33 Z. Lin, Y. Liu and G. Chen, Electrochem. Commun., 2008, 10, 1629-1632.

34 H. Fan, Z. Q. Pan and H. Y. Gu, Microchim. Acta, 2010, 168, 239.

35 X. C. Tan, J. L. Zhang, S. W. Tan, D. D. Zhao, Z. W. Huang, Y. Mi and Z. Y. Huang, Sensors, 2009, 9, 6185.

36 W. Sun, X. Q. Li, Y. Wang, X. Li, C. Zhao and K. Jiao, Bioelectrochemistry, 2009, 75, 170.

37 K. Charradi, C. Gondran, A. Amara, V. Prevot and C. Mousty, Electrochim. Acta, 2009, 54, 4237.

38 H. Sies, Redox Biol., 2017, 11, 613-619. 